\title{
Effect of Heat Treatment Temperatures on Microstructure and Corrosion Properties of Inconel 625 Weld Overlay Deposited by PTIG
}

\author{
Longlong Guo ${ }^{1 *}$, Hualin Zheng ${ }^{1}$, Shaohu Liu ${ }^{2}$, Yueqin Li $^{1}$, Chunyu Feng ${ }^{1}$, Xiaodong Xu ${ }^{1}$ \\ ${ }^{1}$ School of Mechatronic Engineering, Southwest Petroleum University, Chengdou 610500, PR China \\ ${ }^{2}$ Mechanical Engineering College, Yangtze University, Jingzhou 464023, PR China \\ *E-mail: 15108208278@163.com
}

doi: $10.20964 / 2016.07 .97$

Received: 3 April 2016 / Accepted: 1 May 2016 / Published: 4 June 2016

Inconel 625 alloy was cladded on the substrate of AISI 4130 steel using pulsed tungsten inert gas welding (PTIG) technique. The effects of post weld heat treatment (PWHT) temperatures on microstructure evolution and electrochemical corrosion performance of the weld overlay were studied by scanning electron microscopy (SEM), energy dispersive X-ray analysis (EDS) and electrochemical measures. The microstructure of as-welded cladding is mainly composed of $\gamma$-Ni columnar grains and precipitates, such as laves and MC. There is no obvious change in microstructure was observed between the rough welded overlay and the overlay after PWHT at $650{ }^{\circ} \mathrm{C}$. With an increase in PWHT temperature, the size of laves phase appear to decrease, and a small number of needle shaped $\delta$ phase appear in the cladding after PWHT at $750{ }^{\circ} \mathrm{C}$. When the temperature up to $850{ }^{\circ} \mathrm{C}$, a larger number of $\delta$ phase precipitate at interdendritic regions of the cladding. For PWHT at $950{ }^{\circ} \mathrm{C}$, the $\delta$ phase coarsens obviously. The electrochemical testing results indicate that heat treatments have noticeable influence on the corrosion parameters, such as charge transfer $\left(R_{c t}\right)$, self - corrosion potential $\left(E_{c o r r}\right)$, pitting potential $\left(E_{P i t}\right)$, and passivation current density $\left(I_{p}\right)$. The higher heat treatments temperature is detrimental to the corrosion resistance, since heat treatments boost the formation of precipitate phase.

Keywords: Inconel 625; weld overlay; heat treatment; microstructure; corrosion properties

\section{$\underline{\text { FULL TEXT }}$}

(C) 2016 The Authors. Published by ESG (www.electrochemsci.org). This article is an open access article distributed under the terms and conditions of the Creative Commons Attribution license (http://creativecommons.org/licenses/by/4.0/). 